\section{FRESH LIGHT ON THE CAUSE OF CANCER.}

PROF. JOHANNES FIBIGER, of Copenhagen, describes in a long article in the Berliner klinische Wochenschrift for February $\mathbf{I}_{7}$ some experiments which carry our knowledge of the relation between the origin of cancer and external causes a step further. The present writer has been aware of these observations since August, I9II, but they have been in progress since 1907. They have, therefore, been pursued for some five years, which indicates alike the difficulties overcome and the praiseworthy pertinacity of the investigator.

When examining growths found in the stomachs of three wild rats, Fibiger was struck by the presence of nematodes, and he set himself to determine if they stood in causal relationship to the growths or were accidental concomitants. Cancer of the stomach in mice was described by Murray in 1908 from the laboratory of the Imperial Cancer Research Fund, but at an examination undertaken in consequence of a letter from Fibiger, neither he nor we were able to show the presence of nematodes. The growths occurred in rats obtained from some sources and not from others, and their occurrence coincided with the presence of Periplaneta americana. From other sources he was aware of the cockroach serving as a host for round worms. The cockroaches harboured a nematode, and he studied its life-cycle. It lives in the pavement epithelium of the upper portion of the rat's alimentary canal, where it reaches sexual maturity. The eggs containing embryos are passed with the fæces, and on being consumed by the cockroach (either $P$. americana or $P$. orientalis) the embryos are liberated, and wander into the striped muscles of the prothorax and limbs. In these situations they are found after six weeks coiled up trichina-like.

When rats eat infected cockroaches, the larvæ are freed and wander into the squamous epithelial covering of the fundus of the stomach, and occasionally also into the gullet, tongue, and mouth. They do not invade the epithelium covering the rest of the canal. Fifty-seven tame rats were fed on $P$. americana infected with the Spiroptera; in fifty-four the nematode was found in the stomach, in seven the growths which had initiated the investigation were found, and in twenty-nine others there were found the earlier stages of such growths. Feeding rats with eggs containing embryos did not convey the infection. Microscopical investigation showed in the case of seven rats growths resembling the tumour originally observed, together with the certain presence of secondary deposits in other organs in the case of two and possibly of three rats. The structure of the growths was in four out of the seven definitely that of a malignant new growth.

It would appear, therefore, that for the first time malignant new growths have been deliberately produced by experiment through the agency of a living parasite. Fibiger draws the conclusion that the disease is dependent on the presence of No. $226 \mathrm{I}$, vol. 90] the Spiroptera, and, on analogy with other Helminthes, assumes they act by some poison secreted, although he is not prepared to dismiss altogether the possibility of a virus or ultramicroscopical organism being concerned. All the histological pictures found form a continuous series, but they afford no clue to the mechanism of genesis. Important is the observation that the worms were only associated with the primary growths, and were absent from the secondary deposits, showing that the cells had acquired independent powers of growth.

The association of round and other worms with cancerous growths has long been known. Borrel and Haaland described this association for mice from the Institut Pasteur in 1905 for certain growths of the lung and lymph glands. The association of a tape-worm with cancer of the small intestine in mice was described by Bashford and Murray in r9o5. Haaland, when working in the laboratory of the Imperial Cancer Research Fund, published an elaborate communication on the association of a nematode with cancer of the mamma in that animal. He assumed its excretions were the cause of chronic inflammation on which nodular hypertrophy, adenoma, and carcinoma developed. Its life-history - notwithstanding continued attempts made in the hope of being able to attack the problem of causal relationship directly-has not been followed to this day, but it was shown to be different from another nematode occurring in the alimentary canal, both nematodes having been identified by $\mathrm{Mr}$. Shipley and Dr. Leiper. And since then there have been many other references in the literature.

The presence of the worms must not be interpreted in the sense that they are the cause of cancer, as has been done in the lay Press. They probably act as chronic irritants, of which a legion is associated with the development of cancer. They may be animate or inanimate, e.g. mere direct physical injury as in fracture of bone or in the "horn core" of cattle in India, chemical as in paraffin, petroleum, tar, arsenic, and aniline cancer, actinic as in the case of the short hot claypipe, the Kangri, the X-ray, or brand cancers (of cattle). Squamous-celled carcinoma develops in engine-drivers over the shin where the skin has been exposed for years to the direct action of heat. They may be of an infective nature as in Bilharzia for the bladder, the tubercle bacillus where epithelioma develops in an old lupus scar, or Treponema pallidum, as in the association of keratosis linguæ with epithelioma of the tongue. The irritant may be a larger parasite, such as worms.

Borrel has suggested that the latter are the carriers of a specific cancer virus; on the other hand, it has been suggested that the relation for all these irritants is a mediate one in quite a different sense, and that the common factor lies in the capacity of the living cell itself to undergo variations in structure and in powers of growth such as have been demonstrated in propagated tumours when subjected to the repeated irritation produced by transplantation, as described in the reports of the Imperial Cancer Research Fund. It 
is unfortunate that the growths produced experimentally by Fibiger present just as much difficulty in the elucidation of the exact process as do all other natural growths.

In the past the attempt has often been made to produce cancer by subjecting animals to the irritations associated with cancer in man, but without success except possibly in the case of X-rays. As the writer has pointed out, the irritants vary from one mammal to another, and the knowledge of the irritants to which different species and even their individual organs are liable is of very considerable importance, and will require extensive study. Prof. Fibiger is to be congratulated not only in having isolated such an apparent specific irritant, but also, by carefully imitating the natural process, on having produced cancer experimentally through the mediate intervention of a parasite for the first time.

E. F. BASHFORD.

\section{THE INTERNATIONAL AERO EXHIBITION} AT OLYMPIA.

THE development of the details of flying 1 machines between 1908 and the present time is immediately obvious on a visit to the Aero Exhibition; but, quite apart from the higher standard of workmanship, it is also evident that scientific principles are governing the design of aeroplanes to a greater and greater extent. Almost without exception the designs show evidence of the general desire to keep the resistance of the machines as low as possible and so get increased lifting power and speed. It is not any longer necessary to consider the bare possibility of lift, as the shape of the wings is now so good as to give about $20 \mathrm{lb}$. of lift per horse-power, and engines available for aeroplanes can be obtained of horse-powers up to 160 , weighing less than $3 \mathrm{lb}$. per horse-power; such an engine can then carry, roughly, $\mathrm{I} \frac{1}{2}$ tons, a weight greater than that of any existing aeroplane.

The reduction of resistance does not then arise from necessity, but appears to be directly due to the application of scientific principles. The chief saving in resistance arises from fewer stay-wires and in the covering of the fuselage or tail girder of almost all flying machines, although there are notable exceptions, such as the Maurice Farman biplane exhibited. As compared with the first Wright machine, the stay-wiring of modern machines looks comparatively simple, and in biplanes in particular the struts have been lengthened in the direction of the wind. The strength of the struts is often obtained from a circular steel tube, the desired section for low resistance being obtained from it by the addition of wooden tails and headpieces. The difference of resistance due to shaping the tubes may, on a biplane, increase the carrying capacity of the machine to the extent of another passenger.

The covering of the fuselage to make a streamline body has, however, other effects than that of reducing the resistance. The side surface is considerable, and becomes equivalent to a vertical fin; Prof. Bryan in his book on stability has shown mathematically, what $\mathrm{Mr}$. Lanchester No. $226 \mathrm{I}$, VOL. 90] deduced earlier from a combination of experiment and mathematical analysis, that the position of such fins is of the greatest importance when considering the lateral stability of an aeroplane, and that great care must be taken in the arrangement of such surfaces.

One then looks at the exhibits to find how far aeroplane constructors are designing according to the principles of inherent stability, and how far they leave the control to the skill of the pilot. So far as longitudinal stability is concerned, practically all the machines at the normal flying speed satisfy the mathematical requirements for the stability of small oscillations. The essential features of inherent stability are contained in a series of planes inclined fore and aft, with the angle of incidence from plane to plane decreasing progressively from front to back and in addition having the smaller or elevator planes of sufficient area. Most of the machines, such as the Bleriot, $B E$ 2, \&c., have two surfaces, the main wings and a neutral or nearly neutral tail, whilst the Cody prize machine and the Maurice Farman biplane have each three planes due to the addition of a forward elevator.

Part of the tail plane, and usually the greater part, is fixed to the fuselage of the flying machine, and exercises a control which is independent of the pilot, who is left with the adjustment of the remainder for manœuvring. An exception to this subdivision of the elevator occurs in the Breguet machine, where the whole surface is under the immediate control of the pilot. This latter arrangement has the advantage of a powerful control and the corresponding possible disadvantage of depending entirely on the strength of the pilot for the maintenance of attitude. How much the advantage outweighs the disadvantage is obviously a question to be settled later by the majority of constructors, since it is not yet widely adopted.

With the possible exception of flying at low speeds, it would seem that for longitudinal stability flying machines possess a considerable amount of inherent stability, and only call for serious assistance from the pilot in special circumstances, as when the aëroplane is struck by a gust.

Lateral stability, however, receives far greater variety of treatment, and except that all machines provide large control for the pilot, there is, in the machines exhibited, little evidence of unanimity of method. Leaving out the difficult problem of the spiral dive and considering the machines for lateral stability in linear motion, the points of interest in the machines rest with the positions of the vertical fins or their equivalents.

The most usual combination of fins, which may be seen on the Blériot, Deperdussin, and Bristol machines amongst others, is a dihedral angle between the wings, constituting an equivalent fin above the centre of gravity, and the side of the covered body together with the rudder, the latter making a fin behind the centre of gravity. In a recent lecture before the Aeronautical Society, the superintendent of the Aircraft Factory pointed out that the effect of dihedral angle is dependent to a greater or less extent on the arrangement for 